\title{
La crítica hegeliana a la dimensión moral de la ironía en la Filosofía del derecho
}

Julio Marchena

Pontificia Universidad Católica del Perú

Resumen:

La noción de ironía aparece en la Filosofía del derecho de Hegel como una figura del "mal moral" hacia el final de la segunda parte dedicada a la moralidad, junto con otras nociones como la hipocresía, la mala conciencia, el relativismo, etc. Si bien es cierto la crítica hegeliana a la ironía guarda una relación directa con la crítica al romanticismo de Schlegel en sus Lecciones de estética y con la figura del espíritu del "alma bella" en la Fenomenología del espíritu, en la Filosofía del derecho Hegel aborda la dimensión moral de dicha expresión radical de subjetividad que requerirá ser superada desde el punto de vista de la eticidad.

Palabras clave:

Ironía, romanticismo, mal moral, eticidad, ironía del mundo

\section{Abstract:}

The notion of irony appears in Hegel's Philosophy of Right as a figure of "moral evil" at the end of the second part referred to morality, with other notions such as hypocrisy, bad conscience, relativism, etc. While it is true, the Hegelian critics to the irony has a direct relationship with his critics to Schlegel's romanticism in Hegel's Lectures on Aesthetics and with the figure of spirit named "beauty soul" in the Phenomenology of Spirit, in the Philosophy of Right Hegel explores the moral dimension of this radical expression of subjectivity which will be required to be sublated from the standpoint of the ethical life.

Key words:

Irony, romanticism, moral evil, ethical life, irony of the world 
La ironía es una noción compleja que tiene una larga historia como la propia filosofía. Hegel aborda este concepto de manera crítica en diversos pasajes de sus libros y desde diversas perspectivas, lo que la convierte en una noción problemática de múltiples dimensiones. En este artículo voy a analizar el papel de la ironía en la Filosofía del derecho, es decir, voy a abordar la crítica hegeliana a la noción de ironía en el marco de su exposición del concepto de libertad. Veremos que el abordaje que Hegel hace a nuestra noción en este libro guarda relación con la perspectiva estética que desarrolla en su crítica a la ironía romántica de Schlegel en sus Lecciones de estética, o con el desarrollo de la figura del espíritu del "alma bella" que aparece en su Fenomenología del espíritu; etc. Quiero decir que una cabal comprensión de la ironía en Hegel implica establecer la relación entre las diversas dimensiones que va adquiriendo a lo largo del conjunto de la obra de nuestro filósofo.

El caso de la Filosofía del derecho es particular pues la crítica a la ironía es muy categórica. Aparece hacia el final de la segunda parte del libro dedicada a la moralidad en la que Hegel desarrolla la segunda dimensión del concepto de libertad, la particularidad, expresada en la acción moral del sujeto libre, antes de pasar a la última parte del libro dedicada a la eticidad. Aparece exactamente, además, en un comentario al parágrafo 140, en el que relaciona la ironía con otras expresiones de la subjetividad radical como la hipocresía, la mala conciencia, el relativismo, etc., que constituyen figuras del "mal moral".

Una pista para entender el alcance de la crítica hegeliana a la ironía en este libro es tener en cuenta que, si bien es cierto la ironía a la que se refiere es la ironía romántica de fines del siglo XVIII e inicios del siglo XIX, especialmente aquella representada por la figura de Friedrich von Schlegel (y no la ironía que en el origen de la propia filosofía se ha asociado a la figura de Sócrates), en la Filosofía del derecho la crítica no se hace desde una perspectiva estética sino desde una que entiende a la ironía como "figura espiritual" o expresión cultural de una época en la que la libertad subjetiva ha llegado a su máxima radicalidad poniendo en peligro su propio pleno desarrollo. Hegel se encuentra a inicios del siglo XIX con un espíritu de época crítico de la racionalidad de la llustración que lleva a sus extremos la subjetividad 
individual, y experimenta en sí el poder de la imaginación y la absoluta negatividad del mundo objetivo a la vez que disfruta el gozo de ese poderío. Es decir, el descubrimiento de la interioridad del sujeto moderno que se desarrolla en el romanticismo convierte a la libertad negativa del sujeto en un serio problema en términos éticos. La noción de "mal" utilizada por Hegel se refiere, como desarrollaré más adelante, a la actitud del sujeto de no reconocer la necesidad de superar la "(...) subjetividad que se afirma como absoluta" (\$140, FD 241; cursivas del original), es decir, la necesidad de superar la problemática del sujeto ironista desde el punto de vista de la eticidad en el marco de las instituciones sociales que le darían su justo lugar y sentido. La tesis en este artículo sobre la crítica hegeliana a la ironía en la Filosofía del derecho es, pues, que la perspectiva desde la cual dar sentido al valor de la ironía es la de la "eticidad" (Sittlichkeit). Sin embargo, señalaré al final de este artículo algunas otras pistas de superación que el mismo Hegel señala del papel de la ironía en la filosofía.

Este artículo está dividido en cuatro partes. En la primera parte definiré en términos generales el concepto de ironía y el sentido de la crítica hegeliana al punto de vista de la moralidad. En la segunda parte, a partir del análisis de la crítica hegeliana específica de la ironía en Friedrich von Schlegel, pasaré revista a la recepción de la "ironía romántica" por parte de Hegel. Esto me permitirá, además, distinguir con Hegel la diferencia entre la "ironía socrática" y la "ironía romántica" para subrayar el valor filosófico de la primera. En la tercera parte haré una evaluación más pormenorizada del parágrafo 140 de la Filosofía del derecho dedicado a la ironía pues aquí Hegel no solo aclara el tipo de ironía que merece ser criticada sino que, a su vez, la ubica en un mismo grupo junto con otras expresiones de la subjetividad que, como la hipocresía, la mala conciencia, etc., son consideradas "formas morales del mal" (Álvarez Gómez, 2003: 122) y que deben ser superadas desde el punto de vista de la eticidad. Finalmente, en la cuarta parte de este texto, anunciaré brevemente otras posibles respuestas a la problemática de la ironía según Hegel, en especial en sus Lecciones sobre la historia de la filosofía y en la Fenomenología del espíritu. 


\section{§1. La ironía desde el punto de vista de la moralidad'}

La ironía tiene una larga historia, tan larga como la historia de la propia filosofía y entre ellas, a lo largo de su historia, ha habido una relación compleja. Søren Kierkegaard señala en su tesis de 1841, refiriéndose a la ironía en la figura de Sócrates, lo siguiente: "[a]sí como la filosofía comienza con la duda, la vida digna de ser llamada humana comienza con la ironía" (Kier-

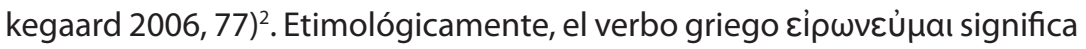
"disimular que se sabe algo", o sea "fingir que se ignora algo" (Ferrater Mora

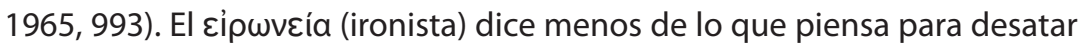
la lengua de su antagonista (Ferrater Mora 1965, 993). En efecto, en los diálogos socráticos en los que Platón representa la figura de su maestro y el carácter de su actividad filosófica que parte de una supuesta ignorancia, vemos cómo la ironía juega un papel central en la forma y en el contenido de aquello que el Filósofo (Sócrates) quiere que se sepa en torno a los asuntos de discusión de común interés, pero sobre todo, acerca de cuál debe ser la mejor actitud que debe uno tomar en la propia vida respecto de dichos asuntos. El punto de partida de la supuesta ignorancia socrática (actitud irónica) expresada en las preguntas que formulaba derivaba en el desarrollo de los diálogos que ponían en evidencia la poca consistencia de los saberes expresados. La ironía socrática tenía una finalidad pedagógica,

1 Si bien es cierto, el punto de vista de la moralidad refiere en un sentido restringido a la noción kantiana de moralidad, entendida esta como la de la fundamentación de un acto moral de manera racional y pura en la ley o en el deber ser, en este artículo lo refiero, en un sentido más amplio, al mundo de la subjetividad o la interioridad que se abre después de superar la primera parte de la Filosofía del derecho dedicada al Derecho Abstracto. En efecto, en el desarrollo de la dimensión universal del concepto de voluntad libre pasamos de la libertad entendida como libertad negativa del agente persona a la dimensión de la particularidad de agente moral que actúa. La libertad se concretiza en la interioridad, reflexividad o subjetividad en la segunda parte del libro titulada Moralidad. En esta dimensión de la voluntad libre podemos encontrar, en efecto, la noción del deber moral del imperativo categórico kantiano que señala lo que debe consistir un acto moral y la crítica hegeliana se presentará al desarrollar una teoría de la acción que abordará el acto del agente moral en su negatividad desde la acción concreta, contingente, finita $y$, finalmente, inscrita en un mundo con otros agentes morales. En este sentido, el punto de vista de la eticidad hegeliana niega y supera (aufheben) esta perspectiva del deber ser de la moralidad kantiana. Mi interés, sin embargo, se dirige a una posibilidad de radicalización de un acto moral que sigue el puro capricho (y en este caso, también iría en contra del rigorismo kantiano) que es el expresado en la ironía romántica, una radicalización del subjetivismo arbitrario.

2 Esta cita corresponde a la tesis XV de la disertación de 1841 titulada Sobre el concepto de ironía en constante referencia a Sócrates. 
era un instrumento retórico empleado en la conversación entre individuos, con un aparente carácter lúdico que apuntaba a cuestiones centrales que iban más allá del propio intento por determinar conceptos. La discusión en torno a los diversos temas de los diálogos deriva en la preocupación acerca de cómo queremos llevar una vida que sea considerada digna de ser vivida, una vida guiada por la reflexión filosófica; es decir, un cuestionamiento de los valores que rigen la propia vida que se mostraba ejemplarmente en el ejercicio dialógico (Hadot 1998, 41).

La modernidad, por su parte, es la época en la que la subjetividad se constituye de tal forma que no solo pone en cuestión la realidad del mundo objetivo respecto del yo que piensa (como en el caso de Descartes) sino que desarrolla esta autonomía en términos de libertad subjetiva (o negativa) que en el contexto en el que ubicaremos nuestro tema de análisis ha llegado a su radicalidad. La ironía del sujeto moderno, la capacidad de encontrar en la subjetividad múltiples y contradictorias posibilidades de acción, es un desarrollo de una forma de libertad del yo que descubre en su subjetivismo extremo un poder para enfrentarse al mundo objetivo y a los otros individuos. En este desarrollo de la radicalidad del yo el ironismo romántico cobra un papel fundamental. La libertad del poeta romántico lleva a sus extremos la libertad subjetiva que la modernidad ha logrado desarrollar con el descubrimiento del potencial de la imaginación y el desarrollo de expresiones literarias como las novelas. Es, sin embargo, problemático también el ejercicio reflexivo del poeta ironista romántico por varias razones que abordaremos con mayor detenimiento más adelante, pues si bien es cierto se resiste al mundo social de la modernidad en la que irrumpe, utiliza la propia libertad que es consustancial al racionalismo ilustrado que el poeta critica, y porque dicha actitud irónico-romántica respecto del mundo sale del ámbito meramente estético e invade un espacio social y político que es lo que Hegel buscará corregir con su crítica. En otras palabras, la ironía se vuelve peligrosa cuando sale de la poesía e invade el mundo social; o, en palabras de Safranski en su libro Romanticismo: Una Odisea del Espíritu Alemán: "Es bueno para la poesía y malo para la política, en el caso que [lo romántico] se extravíe en lo político" (Safranski 2009, 15 en Domínguez 2009, 47). 
Pero vayamos por partes. ¿Cuál es el punto de vista de la moralidad según Hegel en su Filosofía del derecho? La Filosofía del derecho es la obra en la que Hegel aborda el espíritu objetivo; es decir, el concepto de voluntad libre que se despliega en sus tres dimensiones (universalidad, particularidad y singularidad) a lo largo de las tres partes del libro: derecho abstracto, moralidad y eticidad, respectivamente. En este libro Hegel ubica a la ironía en la última sección de la segunda parte dedicada a la moralidad. La moralidad sería el desarrollo de la dimensión de la particularidad o particularización del concepto de voluntad libre en la acción moral concreta.

La esfera de la moralidad es la que corresponde a la segunda dimensión lógica del concepto de voluntad libre en su particularización. Hegel señala que la voluntad en sí (an sich) y para sí (für sich) (\$105, FD 199)³ pasa de ser persona a ser sujeto agente; estamos pues ante el paso de la universalidad a la particularización en la acción concreta. Por eso se puede decir que la subjetividad es la existencia del concepto, el lado real del concepto de libertad, pues se hace acción y se hace voluntad existente.

Sin embargo, el punto de vista de la moralidad en la Filosofía del derecho es el punto de vista de la libertad subjetiva (o "libertad reflexiva" en términos de Honneth ${ }^{4}$ ), es decir, es el punto de vista del sujeto que es libre en tanto decide qué hacer porque quiere y puede hacerlo. Aquí se encontrará el origen de la crítica a la ironía como expresión de mal moral del ejercicio de una voluntad libre subjetivista y radical.

Como he señalado, la ironía aparece hacia el final de la segunda parte del libro dedicada a la moralidad, en la observación al parágrafo 140. Antes de pasar al análisis de los pasajes en cuestión, abordaré brevemente dos tipos de ironía, la romántica y la socrática o clásica. Esto con el fin de determinar mejor el tipo de ironía que Hegel busca criticar.

3 Las referencias de la Filosofía del derecho se inician con el número del parágrafo que corresponde al texto alemán (Hegel 1986a), seguido de la paginación de la traducción de Juan Luis Vermal utilizada para este artículo (Hegel 1999) antecedido con la sigla FD. 


\section{§2. “Ironía romántica" e "ironía socrática”}

La ironía a la que se referirá Hegel en términos negativos está asociada a la figura de Friedrich von Schlegel, uno de los teóricos más importantes del romanticismo. Sin embargo, es interesante también abordar la evaluación que Hegel hace de la "ironía socrática" para rescatar de ella su valor filosófico. Me interesa contraponer ambos tipos de ironía para delimitar mejor los aspectos críticos que encuentra Hegel en la "ironía romántica".

\section{§2.1. "Ironía romántica"}

¿Qué de particular le otorga a la ironía su carácter "romántico"? El romanticismo, como lo señala Safranski, es una larga época en cuyo origen se ve arropado por el cristianismo y que luego procede paulatinamente a su secularización en un mundo desencantado propio de la llustración (Safranski en Domínguez 2009, 47). En su etapa desencantada surgen entre otras las figuras de Friedrich von Schlegel, Hegel y Heinrich Heine, quienes tendrán distintas aproximaciones a este espíritu estético y cultural que estaba ya en decadencia a inicios del siglo XIX. Es más, el propio Schlegel no se consideraba como tal; formaba más bien parte de una "escuela nueva" que miraba con melancolía al romanticismo como expresión de una época pasada y perdida, desde un mundo moderno de la cultura racionalista e ilustrada. Como lo señala Domínguez, el origen cristiano de la corriente estética del romanticismo hizo soñar a la juventud alemana de inicios del siglo XIX, en medio de las turbulencias de la Revolución Francesa, de entusiasmos vehementes por el cambio de época y de sufrimiento y temor por las consecuencias violentas del terror, con un regreso, al menos a nivel creativo, de épocas pasadas que el espíritu liberal y republicano estaba ya dejando en el olvido (Domínguez 2009, 49). Es en este contexto espiritual en el que debe situarse la "ironía romántica". La negatividad de la naturaleza del yo romántico es la negatividad hacia un orden socio-político y cultural en el que no se siente libre. El retorno a la subjetividad es el retorno a un pasado de ideales que los nuevos tiempos están reemplazando por otros, aunque paradójicamente es expresión moderna de una subjetividad que ha llegado, justamente en el siglo XIX, a su mayor radicalidad. 
El ámbito de reflexión de esta actitud que reacciona frente a las turbulencias históricas es inicialmente el de los estudios de crítica literaria y artística. Friedrich von Schlegel escribe el año 1800 un texto titulado Diálogo sobre la poesía en el que critica los ideales de la llustración, asumiéndose no como "romántico" pues ese término corresponde a un tiempo que ya pasó, sino como miembro de una "nueva escuela" (Domínguez 2009, 48); mientras que Heine en 1835 en su libro La escuela romántica se reconoce como integrante de "La Joven Alemania" ("Das Junge Deutschland") (Domínguez 2009 , 48). Hay un aspecto negativo del romanticismo que, en el fondo, se quiere revalorar; una especie de aura melancólica que termina expresándose en la intuición de que la vida es un juego. Safranski señala lo siguiente a este respecto:

(...) es necesario haber comprendido que quizá la vida en general no es otra cosa que un juego. Es cuestión de que uno mismo se ponga en escena como un actor del gran juego del mundo (...) De ahí procede el juego de la ironía en los románticos, sobre todo en Friedrich Schlegel (Safranski 2009, 58).

Es decir, la ironía debe llevar a "(...) la bella confusión de la fantasía, al caos originario de la naturaleza humana (...)" (Safranski 2009, 58) que es lo propio del trabajo poético, de la creación de mundos con las palabras. La ironía, a diferencia de la expresión socrática como actitud personal intersubjetiva, se convierte inicialmente en el romanticismo en una herramienta retórica pues "[i]ronía es producir frases comprensibles que conducen a lo incomprensible cuando las consideramos más de cerca" (Safranski 2009, 60).

Vistas así las cosas, cabría insistir en la pregunta: ¿cuál es el problema moral que ve Hegel en la "ironía romántica" y por qué le dedica un lugar importante en su Filosofía del derecho? Hegel tendría todo el derecho de criticar el aspecto estético de la ironía si ella fuese solo expresión de este carácter negativo del esteta que no se halla en el nuevo mundo que se va imponiendo. Efectivamente Hegel lo hace, pero porque ve que no es solo una cuestión meramente estética, sino que es un problema que se va complejizando, institucionalizando y convirtiéndose en un asunto político y cultural. Domínguez lo aclara muy bien con este pasaje: “La conversión de 
la poética de lo romántico en programa de política cultural en los centros de poder de Alemania es lo que estimula la crítica de Hegel desde la filosofía (...)" (Domínguez 2009, 49).

Pero no sólo es un problema cultural para Hegel. La "ironía romántica" se instala en los fueros de la propia filosofía con la arrogancia que solo un espíritu libre como el de Schlegel reclama.

"La filosofía", escribe Schlegel, es "la auténtica patria de la ironía", es una "bufonería trascendental"; está vivificada "por un temple de ánimo que lo abarca todo con la mirada y que se eleva infinitamente sobre todo lo condicionado, también sobre el propio arte, virtud o genialidad" (Safranski 2009, 61).

Es este tipo de filosofía que Hegel considera superficial lo que fundamenta el "mal" en su época (\$140, Observación, FD 241). El "mal moral" es esta actitud filosófica que desestabiliza el trabajo serio y arduo del concepto, pero que no es meramente superficial. Justamente el problema que encuentra Hegel es que el ironista es consciente de dicha superficialidad o, mejor dicho, de la vanidad de su trabajo, no solo del mundo objetivo que lo niega por inesencial, sino del propio mundo interior; y en esa vanidad goza irresponsablemente.

El romántico Schlegel es un hombre moderno que lleva a sus extremos el poder de la libertad subjetiva que niega la realidad objetiva; pero que no es inocente en tanto logra que esa actitud se manifieste en el mundo, se haga acción en un tipo de vida estética concreta; en ese sentido, se hace política. Diría en este punto que esta actitud ironista resurgirá mucho tiempo después en las llamadas filosofías postmodernas de fines del siglo XX como la de Richard Rorty, en el marco de la crítica de los grandes sistemas filosóficos desde una perspectiva post-metafísica ${ }^{5}$.

5 Un texto sugerente a este respecto es su clásico Contingencia, ironía y solidaridad. Cfr. Rorty 1991, 991-139. 


\section{§2.2."Ironía socrática”}

Por otro lado, toca distinguir la "ironía romántica" con la que le sirvió de modelo inspirador: la "ironía socrática". Para evaluar desde la perspectiva hegeliana la noción de la "ironía socrática" y distinguirla de la "romántica" retomaré la definición etimológica del término. La ironía significa "disimulo" o el hecho de "disimular que se sabe algo" o "fingir que se ignora algo" (Ferrater Mora 1965, 993). ¿En qué se puede parecer esta ironía a la romántica que he presentado líneas arriba? Autores como Jenkélévitch entienden que ambos tipos de ironía responden a un mismo espíritu filosófico, en el sentido de ser críticos de los supuestos saberes y preocupados por ser abiertamente provocadores y temerarios pues "(...) la ironía (...) no le teme a las sorpresas, juega con el peligro. Actúa su falso temor y nunca se cansa de derrotar a ese delicioso peligro al que mata una y otra vez" (Jenkélévitch $2015,11)$. En efecto, esta forma de entender tanto la ironía como la figura y el papel filosóficos de Sócrates, mostrarían algún tipo de coincidencia en la confrontación con la realidad dada, entre la ironía "romántica" y la "socrática".

Sin embargo, hay por lo menos dos cuestiones de base que harían insostenible esta interpretación. El contexto histórico particular en el que ambos tipos de negatividad se desarrollan haría difícil equipararlos, sobre todo, teniendo en cuenta que el rasgo distintivo en ambos casos es una particular experiencia de la subjetividad. Se podría, eventualmente, y Hegel lo hace, reconocer el inicio de la filosofía y de la subjetividad en la actitud irónica socrática (cuestión que, como anoté líneas arriba, también Kierkegaard comparte), pero no podemos comprender a cabalidad lo que hubiera sido ejercer dicha ironía en el mundo del yo moderno, salvo su aspecto desestabilizador.

Hegel se cuida de quitarle el aura "romántica" a las interpretaciones sobre la figura de Sócrates pero defiende su actitud filosófica de vincular el conocimiento y la vida individual, la búsqueda del saber desde la interioridad y la coherencia de la acción moral como las cuestiones que constituyen el mismo ejercicio filosófico socrático. Kierkegaard también anotará en sus reflexiones sobre la ironía la diferencia del temple irónico socrático, clásico 
y equilibrado, frente al turbulento, pasional y moderno del romanticismo (Kierkegaard 2006, 68).

El aspecto formativo del ejercicio irónico, además, aborda la ironía como recurso y como fin en sí mismo. La motivación socrática de hacer despertar a Atenas para hacerla pensar críticamente era una motivación impulsada por la búsqueda del saber que en el caso concreto de la discusión real entre individuos, cobraba forma no solo como recurso comunicativo, en la expresión irónica, sino como método reflexivo, crítico y filosófico del individuo que busca razones para tratar de definir conceptos. De ahí que este ejercicio epistémico iba de la mano con una actitud crítica y no dogmática que configuraría el legado socrático-platónico de la figura del Filósofo. Esto, como lo veremos más adelante en la crítica hegeliana, no es lo esencial en la actitud del ironista romántico. El juego en el que goza su actitud destructiva de lo real objetivo desde el poder infinito de la libertad de su subjetividad interior es no solo provocador sino distinto del proyecto formativo de la filosofía.

\section{§3. La ironía como mal moral en la Filosofía del derecho de Hegel}

Después de haber evaluado la distinción que Hegel hace entre los tipos de ironía ya presentados, pasaré en esta parte a abordar más precisamente algunos parágrafos de la Filosofía del derecho sobre su crítica a la ironía.

En la segunda parte del libro titulada "La moralidad", la voluntad libre se manifiesta en tres momentos que corresponden a las tres secciones de dicha parte. La voluntad se expresa como acción (die Handlung) que en un primer momento se cree y se siente libre (de manera negativa) hasta darse cuenta de las consecuencias no calculadas de su actuar. El propósito y la responsabilidad (o la culpa) son tematizados en esta primera expresión de la voluntad libre en su dimensión de la particularización (Besonderung) en la acción concreta (\$115-118, FD 209-213). En un segundo momento, correspondiente a la sección dedicada a la intención y el bienestar (o la felicidad), la acción ya toma en cuenta todas las posibles consecuencias de su proceder para alcanzar la felicidad sin culpa ni arrepentimiento. La voluntad subjetiva cuida que su propia acción libre no cometa actos de 
los cuales lamentarse (\$119-128, FD 214-224). Finalmente, en el tercer momento, titulado "El bien y la certeza moral" (Das Gute und das Gewissen, \$129-140, FD 225-259), cae la voluntad subjetiva en la cuenta de que esa felicidad perseguida por la acción libre no necesariamente busca el bien de todos, sino el beneficio particular. La contraposición entre el bien de todos, que se comprenderá recién desde el punto de vista de la eticidad, en este momento se contrapone al logro parcial del despliegue de la libertad que se refiere a la certeza moral. La acción que aparece en esta última parte de la moralidad es una acción segura de su pureza, de su autonomía y de las buenas razones que la motivan, que expresan una radicalidad que Hegel señala por perniciosa desde el punto de vista social o de la eticidad. En efecto, la certeza que motiva la acción subjetiva requiere de la mediación social que le haga entender la unilateralidad de su pretensión moral universal, que concretice su abstracción formal y que la haga darse cuenta de los riesgos que una acción con esas características puede provocar. En este contexto de la crítica hegeliana aparece la ironía, en el último parágrafo de esta parte última de la moralidad.

Es, en realidad, en la extensa observación al §140 donde presenta estas figuras extremas de subjetividad, que son un mal moral:

a) El actuar con mala conciencia que se da cuando se actúa sabiendo que hay una universalidad que no se está queriendo seguir, ya sea por capricho o por un sentimiento de derecho y deber. Esto es distinto al actuar por ignorancia o desconocimiento (\$140, Observación, FD 242-244).

b) La hipocresía, que implica una verbalización de la acción hecha con mala conciencia que niega su maldad moral. El afirmar para otros que una acción moral es buena cuando no lo es implica un par de cosas importantes. Por un lado, que es un autoengaño basado en tomar en consideración otros distintos comportamientos correctos como lo que justifica una mala acción concreta. Si yo me porto de manera piadosa o me he comportado bien en diversas ocasiones, entonces frente a esta acción concreta que sé que es mala o que se ha determinado por una mala conciencia, estoy justificado para afirmarla como buena. Esta afirmación es lo que implica la falta de verdad de la acción moral 
hecha con mala conciencia. Enunciarla frente a los demás es un fraude. En todo caso, lo más grave de todo es que la subjetividad sabe que, en cuanto negatividad abstracta, toda determinación le está sometida y proviene de ella, de la propia subjetividad. Aquí radica la posibilidad de la negatividad infinita de la subjetividad, que se representará más adelante con la ironía (\$140, Observación, FD 244).

c) El probabilismo o relativismo, como figura de la hipocresía, utiliza como 'garante' lo que alguna o algunas autoridades han manifestado en la defensa de algún tipo de acción; sin reconocer que esa opinión es una frente a múltiples y variadas. Se trata de no ver dicha multiplicidad para adoptar arbitrariamente una acción previa y externamente justificada. A pesar de que requiere fundamentación, ante las diversas, distintas y numerosas razones que a su vez son de autoridades en la materia, al final quien decide es la propia subjetividad (\$140, Observación, FD 244-245).

d) La buena voluntad o la buena intención que justifica o santifica los medios utilizados. Esto es otra forma de querer el bien abstracto. Las buenas intenciones se defienden, justamente, por esta abstracción del bien buscado; en contra de la consideración del análisis de los medios que deben ser concretamente buenos. La buena voluntad de querer el bien abstracto es otra figura del mal moral. El bien abstracto no está determinado; la subjetividad le da un contenido al bien; $y$, en ese sentido, es producto de la más peligrosa arbitrariedad que efectivamente pueden llevar a crueldades de diverso tipo (\$140, Observación, FD 245-249).

e) La convicción o la opinión subjetiva que se asume como verdadera: a pesar de reconocer su perspectivismo no se le acepta como tal y se actúa en consecuencia (\$140, Observación, FD 249-253). Y finalmente:

f) La ironía que es "(...) la forma más elevada en que se aprehende y se expresa perfectamente esta subjetividad" (\$140, Observación, FD 253).

Aquí aborda primero el hecho que es tomada la ironía como heredera del sentido platónico (o socrático-platónico) del término para distinguirlo de su heredera, la "ironía romántica”: "Platón no trataba sólo a aquella conciencia [de los saberes del sentido común] de modo irónico, y no a la idea misma" 
(§140, Observación, FD 253). Además, la ironía, señala Hegel, se expresa, como forma retórica, en el diálogo y entre personas; con lo cual marca una diferencia con la dialéctica especulativa que aborda la idea misma que menciona en la cita precedente.

En este punto hay un giro de Hegel hacia la interpretación de la "ironía romántica" hecha por Solger quien reconoce el carácter "arrogante" de la ironía de Schlegel en tanto "subjetividad que se sabe como lo superior" (\$140, Observación, FD 253, nota a pie); pero que, justamente por ello guarda una afinidad con la auténtica dialéctica (o "verdadera ironía", sobre la que señalaré algunas ideas al final de este texto) en tanto es expresión de una subjetividad que por su arrogancia está dirigida a lo más alto; pero que desde una perspectiva "metafísica" solo es un momento de la finitud que no dice nada desde la perspectiva de la divinidad instalada en un más allá del que no podemos decir nada. Por ello, el romántico reconoce (según Solger) que lo más elevado es la divinidad que se revela en la desaparición de nuestra realidad. En los grandes personajes históricos y literarios cobra dicha ironía un carácter trágico que cumple además, irónicamente, un papel formativo: nos elevamos con la caída del mejor.

Hegel discrepa de este análisis, aunque es interesante explorar la relación del carácter verdadero de la "ironía romántica" con el punto de vista histórico o metafísico del propio ejercicio dialéctico (tarea que no haré aquí pero dejaré señalada). Lo que sí me interesa subrayar en la crítica hegeliana a Solger es que en las tragedias griegas se contraponen dos fuerzas éticas de gran valor, que en su contraposición hace surgir lo justo y lo injusto de cada una; y la idea ética resulta purificada y triunfante y penetra reconciliada en nosotros. No nos elevamos con la caída del mejor y permanecemos en el ámbito finito que es, al parecer, el que nos corresponde; sino que nos elevamos con lo verdadero, con la idea ética que la tragedia enseña y que hace posible el perdón y la reconciliación.

En la crítica hegeliana a la ironía se vislumbra la necesidad de la superación del mal moral de la ironía desde el punto de vista de la eticidad que niega y supera la moralidad. Es, por la propia naturaleza de "mal moral" de la ironía, una superación que exige el ejercicio pleno de la libertad subjetiva, ya no 
desde el punto de vista limitado y, en este caso, limitante del punto de vista moral. Me explicaré a partir de la siguiente cita hegeliana que tiene un sentido irónico notable:

En la conciencia irónica en que hago sucumbir lo más elevado sólo gozo de mí mismo. Esta figura no es sólo la de la vanidad de todo contenido ético del derecho: los deberes, las leyes (...) sino que se agrega también la forma de la unidad subjetiva, la de saberse a sí mismo, como la unidad de todo contenido y en ese saber saberse absoluto (\$140, Observación, FD 255).

Esta vanidad a la que ha llegado la voluntad subjetiva al afirmar y al considerar en su acción esta vanidad del mundo se corresponde, pues, con la propia vanidad del goce desinteresado del sujeto irónico que juega constantemente con la realidad y con su propia vanidad. Es, pues, necesaria la superación de la ironía.

\section{§4. Otras pistas hegelianas de superación de la ironía}

Llegados a este punto, mencionaré solo brevemente algunas otras posibles respuestas a esta necesidad de superación de la ironía en otras dos obras de nuestro filósofo. En la Fenomenología del espíritu Hegel desarrolla una figura del espíritu que llama "alma bella". (Hegel 1987, 368-392). Una figura del espíritu es "(...) una manifestación cultural o "visión del mundo" compartida por una cultura en un momento histórico determinado. Los miembros de una cultura participan en la constitución de la figura del [e] spíritu, pero no son sus inventores" (Alfaro 2019, 57).

Esta figura del "alma bella" guarda relación con la ironía en tanto también esta es una expresión social, no meramente individual, como ya lo señalé al hablar de la "ironía romántica". Sin embargo, lo propio de la figura del "alma bella" es que es "(...) incapaz de actuar en el mundo por miedo a quebrar su armonía interna" (Alfaro 2019, 58). Digamos que es una autoconciencia desgarrada que, consciente de sus infinitas posibilidades de acción moral, decide replegarse en la propia subjetividad. De manera similar que en la Filosofía del derecho se requiere una superación en el plano ético o social. 
Finalmente hay un tipo de ironía en Hegel distinta a la que critica tan categóricamente: la "ironía del mundo" que se asocia con el ejercicio dialéctico. Hay, pues, una ironía dialéctica que Hegel la entiende como estructural a la realidad que permite el desarrollo de las contradicciones inmanentes que llevarán al dinamismo de la misma y que, en nuestro contexto, posibilitarían el paso de la ironía desde el punto de vista de la moralidad a un punto de vista histórico o metafísico.

En sus Lecciones sobre la historia de la filosofía Hegel señala lo siguiente en el contexto de una reflexión sobre la ironía socrática: "Toda dialéctica hace valer aquello que debe valer como si fuese válido ("läßt das gelten, was gelten soll als ob es gelte"), deja que la destrucción interna se desarrolle en ello - la ironía universal del mundo ("sich daran entwickeln, -allgemeine Ironie der Welt")" (Hegel 1995: 54; 1986b: 460). Es decir, y en esto sigo a Casas Dupuy, "(...) la dialéctica incorpora una ironía estructural, en el sentido de que deja que las contradicciones internas de la realidad se desarrollen" (Casas Dupuy 1999, 23).

Aquí veo una pista para explorar la crítica que el propio Hegel hace en el pasaje correspondiente de la Filosofía del Derecho a la interpretación de la "ironía romántica" de Solger y Schlegel. Pareciera que desde una perspectiva histórica se puede (y debe) entender la moralidad y la ironía como momentos de un devenir que dialécticamente cobran sentido, muchas veces de manera trágica en el sujeto irónico que se resiste a desarrollar su libertad más allá de su perspectiva moral unilateral o, en otros términos, que no decide ejercer su plena libertad y que adopta la libertad negativa del puro goce subjetivo.

\section{$\S 5$. Conclusiones}

En este trabajo he analizado la crítica a la noción de "ironía romántica" que aborda Hegel en su Filosofía del derecho como una forma de "mal moral" en tanto se expresa desde la perspectiva de la moralidad, ámbito del desarrollo de una libertad negativa o reflexiva que se recoge en su interioridad y que plantea riesgos en el ámbito moral y cultural. Fue necesario hacer una 
distinción entre dicha ironía y la "socrática" para entender el sentido filosófico de esta última y subrayar la distinción básica entre ambas en cuanto a la finalidad de dicha actitud espiritual. Mientras que la ironía en Sócrates se expresa en un diálogo personal que busca que se tome conciencia de la necesidad de que la pregunta por los conceptos sea una pregunta por nuestro propio carácter, una pregunta por nuestra conversión en términos filosóficos y morales, en los románticos es un juego del gozo que se entusiasma por su carácter negativo respecto de la vanidad del mundo objetivo y de la propia actitud ironista. No hay una preocupación formativa en el caso de este último tipo de ironía. Hegel detecta en la actitud ironista un problema espiritual que debe ser superado.

Después del análisis de los últimos pasajes de la moralidad en la que se caracterizan las distintas formas de mal moral, encuentro que la necesidad de superación de la ironía implica el ejercicio de la propia voluntad subjetiva para considerar la acción desde la perspectiva de la eticidad, las normas y leyes sociales, que implicaría la toma de conciencia de la unilateralidad del subjetivismo; pero que no es la única posible vía de superación de la ironía. Desde otras perspectivas, que anuncio como rutas de investigación posteriores, vislumbro el carácter irónico de la propia perspectiva histórica o metafísica hegeliana que entiende a la ironía de la moralidad como un momento de superación dentro de una ironía del mundo que, a diferencia de la lectura de Solger sobre la ironía se podría aprehender conceptualmente, más allá de que en la historia de los individuos y los pueblos, en la historia del espíritu, muchas veces se vislumbra recién al final, después del carácter trágico del devenir. 


\section{Bibliografía}

Alfaro, Carlos Víctor, 2019. Similitudes y diferencias entre la "ironía romántica" y la figura del espíritu denominada "alma bella" en la filosofía de Hegel, Ágora, Papeles de filosofía, 38 (1), 57-78.

Álvarez Gómez, Mariano, 2003. El concepto de bien en Hegel. En: El retorno del espíritu: Motivos hegelianos de la filosofía práctica contemporánea, ed. Miguel Giusti. Lima: Fondo Editorial de la Pontificia Universidad Católica del Perú, 121-135.

Casas Dupuy, Rosario, 1999. Apuntes sobre la crítica hegeliana de la ironía, Ideas y Valores, (110), agosto, 21-31.

Domínguez, Javier, 2009. Lo romántico y el romanticismo en Schlegel, Hegel y Heine: Un debate de cultura política sobre el arte y su tiempo, Revista de Estudios Sociales (34). 46-58.

Ferrater Mora, José, 1965. Diccionario de filosofía. Tomo I. (5a. ed.). Buenos Aires: Sudamericana.

Hadot, Pierre, 1998. ¿Qué es la filosofía antigua? (Trad. de: Eliane Cazenave). Ciudad de México: Fondo de Cultura Económica.

Hegel, G. W. F., 1986a. Grundlinien der Philosophie des Rechts oder Naturrecht und Staaswissenschaft im Grundrisse, Werke in zwanzig Bänden, 7. Frankfurt: Suhrkamp.

- 1986b. Vorlesungen über die Geschichte der Philosophie, I, Werke in zwanzig Bänden, 18. Frankfurt: Suhrkamp.

- 1987. Fenomenología del Espíritu. [Trad.: Wenceslao Roces.] México D.F.: Fondo de Cultura Económica.

- 1995. Lecciones sobre la Historia de la Filosofía, Tomo II. [Trad.: Wenceslao Roces]. México D.F.: Fondo de Cultura Económica.

- 1999. Principios de la Filosofía del Derecho o Derecho Natural y Ciencia Política. [Trad.: Juan Luis Vermal]. [2da. Edición]. Barcelona: EDHASA.

Honneth, Axel, 2014. El derecho de la libertad: Esbozo de una eticidad democrática. [Trad.: Graciela Calderón]. Buenos Aires: Katz Editores.

Jankélévitch, Vladimir, 2015. La ironía. [Trad. de: Carlos Schilling]. Buenos Aires: El Cuenco de Plata.

Kierkegaard, Søren, 2006. Escritos. Volumen 1: De los Papeles de Alguien que Todavía Vive. Sobre el Concepto de Ironía. [Traducción: Darío González y Begonya Saez Tajafuerce]. [2a ${ }^{a}$ edición]. Madrid: Trotta.

Rorty, Richard, 1991. Contingencia, ironía y solidaridad. [Trad.: Alfredo Eduardo Sinnot]. Barcelona: Paidós.

Safranski, Rudiger, 2009. Romanticismo: Una Odisea del Espíritu Alemán. [Trad.: Raúl Gabán]. Barcelona: Tusquets Editores, S.A. 